\section{$\underset{\substack{\text { hommes } \\ \text { \& migrations }}}{ }$}

\section{Hommes \& migrations}

Revue française de référence sur les dynamiques

migratoires

1289 | 2011

Les frontières du sport

\title{
Léonora Miano, Blues pour Élise
}

Plon, 2010, 200 pages, 18 euros

\section{Élisabeth Lesne}

\section{(2) OpenEdition \\ 1 Journals}

\section{Édition électronique}

URL : http://journals.openedition.org/hommesmigrations/835

DOI : 10.4000/hommesmigrations.835

ISSN : 2262-3353

\section{Éditeur}

Musée national de l'histoire de l'immigration

\section{Édition imprimée}

Date de publication : 1 janvier 2011

Pagination : 156-157

ISSN : 1142-852X

\section{Référence électronique}

Élisabeth Lesne, «Léonora Miano, Blues pour Élise », Hommes \& migrations [En ligne], 1289 | 2011, mis en ligne le 29 mai 2013, consulté le 22 septembre 2020. URL : http://journals.openedition.org/ hommesmigrations/835; DOI : https://doi.org/10.4000/hommesmigrations.835

Ce document a été généré automatiquement le 22 septembre 2020.

Tous droits réservés 


\title{
Léonora Miano, Blues pour Élise
}

\author{
Plon, 2010, 200 pages, 18 euros
}

\section{Élisabeth Lesne}

\section{RÉFÉRENCE}

Léonora Miano, Blues pour Élise, Plon, 2010, 200 pages, 18 euros

1 “La France telle que vous ne l'avez jamais lue." Une formule parfaite, de Léonora Miano, pour présenter sur son blog son cinquième roman, Blues pour Élise. Un roman qui se passe à Paris et dont tous les personnages ont des "visages d'ambre et d'ébène", à une exception près.

2 Le sous-titre, "Séquences afropéennes. Saison 1", annonce la couleur et la structure, entre le recueil de nouvelles, la série télé et l'album de neo-soul. Tous les personnages ont droit à leur séquence et à leur ambiance musicale ; au fil des pages se révèlent leurs liens, familiaux, amicaux ou amoureux.

3 Le livre une fois refermé, on quitte avec regret une bande de copines, les "Bigger than life", des filles "crêpues, portant des prénoms non alignés, des patronymes à l'ancrage lointain" : Akasha, Amahoro, Malaïka et Shale. Solidaires depuis la fac, elles ont des racines subsahariennes et la nationalité française, elles travaillent, aiment les fringues et les bars où se retrouver pour se remonter le moral. Elles se battent avec leurs cheveux et parfois contre les kilos, se dorlotent à la "soul therapy" et, comme toutes les filles de la trentaine, leur grande affaire, c'est l'amour.

4 Alors, plus léger que les autres ${ }^{1}$ ce dernier roman ? Non, pas plus que ne l'est l'amour, passé le temps des premiers éblouissements. Très vite affleurent les peurs (quand le corps n'est pas au top de sa splendeur), les doutes (quand Malaïka s'éprend d'un immigré venu d'un pays d'Afrique anglophone et que plane la crainte d'un "mariage gris"), les malentendus (quand une "fantaisie impromptue" déstabilise l'amoureux d'Amahoro), les déceptions (quand Akasha découvre les préférences sexuelles de son grand amour), les secrets de famille (quand Elise, avant de convoler à nouveau, veut révéler à sa fille Shale les circonstances de sa naissance). 
5 Léonora Miano revient dans ce roman sur un thème qui lui est cher - "une sorte d'obsession", dit-elle -, les relations difficiles entre les Antillais et les Subsahariens. Notamment à travers l'histoire de Marianne, la mère d'Akasha, une Martiniquaise "trop noire pour que les siens lui prédisent un avenir lumineux" et qui avait décidé de se trouver "un homme venu de la Terre Mère, habitué à voir du noir, où que ses regards se posent".

Plus léger, ce dernier roman? Non, on retrouve la même force chez l'auteur, pas question de gémir sur son sort ou sur les séquelles de la colonisation. Quand Ernest dit à Estelle que “l'Europe n'aimait pas ses Noirs, leur préférant les Américains", Estelle ne mâche pas ses mots, "pour elle, les Afropéens étaient en partie responsables de leur situation. Contrairement aux Afro-Américains qui avaient lutté pour se faire respecter chez eux, ils rechignaient à s'affirmer européens. Or, s'ils ne se sentaient pas à leur place en Europe, ils ne pouvaient s'attendre d'y être traités en autochtones [...]. Ils devaient mettre un terme à leurs tergiversations identitaires, cesser d'être nommés et légitimés par la majorité. Ils devaient s'inventer, s'imposer, se dire..." Une belle énergie aussi et une grande aptitude au bonheur : “À vivre sans plaisir, on assombrissait son aura." Au présent, cette phrase devient une règle de vie!

7 Blues pour Elise ne manque pas d'humour non plus. Par exemple, quand Léonora Miano ironise sur "la taille 38, burqua de la femme occidentale", et sur la déprime de l'homme blanc: "Depuis un moment, [il] poussait, lui aussi, son sanglot. Il souffrait. Le capitalisme dérégulé l'oppressait, les traders le mettaient sur la paille [...] il se demandait à quoi ça avait servi, tout ça: le code noir, le code de l'indigénat, ça lui faisait une belle jambe, il avait honte de ses aïeux, voulait tout effacer [...]."

8 Et les hommes noirs? Attention, fragile! Un rien les déstabilise. De plus, l'élection du beau Barack Obama les force à mettre au masculin la devise "À l'impossible femme est tenue, surtout la noire." Et à jouer l'égalité des sexes dans le couple...

9 Ces chroniques urbaines d'une France plurielle, Léonora Miano les a écrites dans une langue musicale et hybride qui bruisse de camerounismes, créolismes, anglicismes et autres trouvailles, à lire en écoutant biguine, zouk, rap, funk, soul... pour mieux entrer encore dans son univers. Vivement la suite, la Saison 2 !

\section{NOTES}

1. Léonora Miano écrit une trilogie consacrée aux blessures de l'Afrique subsaharienne : L'Intérieur de la nuit (2005), Contours du jour qui vient (2006) et Les Aubes écarlates (2009). Elle a déjà parlé des Afropéens dans un roman complexe, Tels des astres éteints (2008), et dans un recueil de nouvelles destiné aux collégiens et aux lycéens (et à tout le monde, d'ailleurs), Afropean Soul et autres nouvelles. 